Article

\title{
A Novel Approach for Predicting the Height of the Water-Flow Fracture Zone in Undersea Safety Mining
}

\author{
Bing Dai $\odot$ and Ying Chen *(1) \\ School of resources environment and safety engineering, University of South China, Hengyang 421000, China; \\ daibingusc@usc.edu.cn \\ * Correspondence: csu_chenying@csu.edu.cn; Tel.: +86-18569069231
}

Received: 30 December 2019; Accepted: 20 January 2020; Published: 22 January 2020

\begin{abstract}
The height of the water-flow fracture zone (WFZ) is an important reference for designing the size of a waterproof crown pillar. Once the WFZ is connected with the sea, there will be catastrophic consequences, especially for undersea mining. This study suggests using a rotating forest (RoF) model to predict the height of the WFZ for the evaluation of the size of a waterproof crown pillar. To train and test the RoF model, five indicators with major influencing factors on undersea safety mining were determined, 107 field-measured mining datasets were collected, $75(70 \%)$ datasets were used for training, and $32(30 \%)$ datasets were used for model testing. At the same time, the random forest ensemble algorithm (RFR) and support vector machine (SVM) models were introduced for comparison and verification; in the end, the tested results were evaluated by RMSE (root-mean-square error) and $\mathrm{R}^{2}$. The comparison shows that the predicted results from the RoF model are significantly better than those from the RFR and SVM models. An importance analysis of the impact indicators shows that the mining height and depth have significant impacts on the prediction results. The development height of the WFZ in undersea safety mining was predicted via the RoF model. The predicted results via the RoF model were verified by field observations using panoramic borehole televiewers. The RoF prediction results are consistent with the observation results at all depths. Compared with the other two models, the RoF model has the smallest average absolute error at $2.87 \%$. The results show that the RoF model can be applied to predict the height of the WFZ in undersea mining, which could be an effective way of minimizing the mineral resource waste in the study area and in other similar areas in the world under the premise of mine safety.
\end{abstract}

Keywords: machine learning; the water-flow fracture zone; undersea mining; the rotation forest ensemble algorithm; the random forest ensemble algorithm; the SVM

\section{Introduction}

With the rapid growth of the economy, the demand for mineral resources has continued to increase [1]. However, as easy-to-mine orebodies are gradually exhausted, orebodies with complicated mining conditions, such as broken orebodies, high-cold orebodies, deep orebodies, and underwater or seabed orebodies, are becoming important mining targets [2-4]. With the development of technology and equipment upgrades, the exploitation of underwater mines is gradually increasing. After mining an underwater orebody, a goaf can be produced, which will cause the overburden to move, deform, and even break down [5], making it easy to form an overburden mining fracture zone, which may lead to water pouring into the mine, causing water inrush accidents [6]. According to the statistics of the government accident investigation system of the State Administration of Work Safety of the People's Republic of China [7], from 2003 to 2017 there were 561 mine water-inrush accidents in China, which led to 2875 deaths, as shown in Figure 1. The occurrence of water-inrush accidents in mines not only causes casualties and resource losses but also damages the original water and land 
environment, can cause a ground collapse, and can affect the ecological environment around the mining area. Therefore, it is of great safety significance to pay close attention to the height of the water-flow fracture zone in underwater mines.

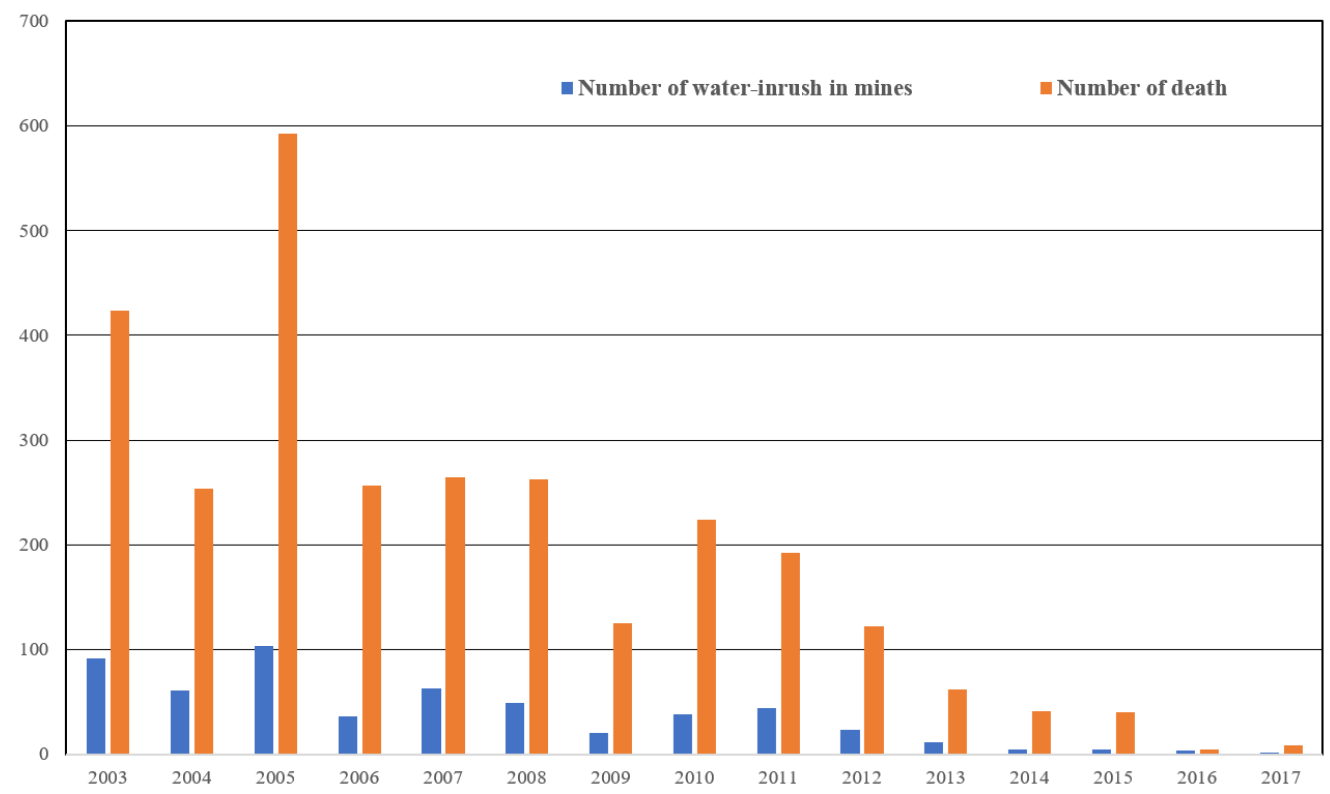

Figure 1. Statistics on mine water-inrush accidents in China.

Many approaches have been adopted to estimate the height of the water-flow fracture zone (WFZ). These approaches can be grouped as empirical equations, theoretical calculations, field measurements, physical and numerical simulations, and artificial intelligence methods.

The Chinese, British, and Japanese governments have issued empirical prediction equations based on mining practices [8]. Most of these empirical equations are derived from the accumulation of field experience. For safety reasons, these empirical prediction equations exaggerate the thickness of the crown pillar and lead to the waste of resources.

Beyond these equations, researchers have proposed theoretical calculations of the WFZ based on mining subsidence theory [9], the law of overlying stratum movement [10], and permeability changes in the rock strata [11]. Due to the complexity of the assumption conditions in theoretical calculations and the mining environment in the field, most of these results do not have a wide applicability.

Physical and numerical simulations are methods used to predict the heights of WFZs [12-15]. Many numerical simulation methods have been proposed to determine the height of the WFZ, such as PFC (Particle Flow Code) [16], UDEC (Universal Distinct Element Code) [17], 3DEC (3 Dimension Distinct Element Code) [18], FLAC (Fast Lagrangian Analysis of Continua) [19], and ANSYS [20]. However, these numerical simulations require many input parameters that may require approximations or assumptions, and physical simulations are time consuming and expensive.

Field measurements, such as the downhole water injection leak detection method, acoustic computed tomography (CT), the borehole TV method, the high-density resistivity method, the drilling mud testing system, and transient electromagnetic methods [21-25], have been used individually or in combination to measure the height of the WFZ. Due to the complexity of underground and underwater mining environments and equipment operations, field measurements are time consuming and expensive, similar to physical simulations.

In recent years, numerous artificial intelligence technologies have been utilized to predict the height of the WFZ, such as artificial neural networks (ANNs) [26], support vector machines (SVMs) [27], random forest regression (RFR) [28], and the gray relational analysis analytic hierarchy process (GRA-AHP) [29]. These technologies can synthetically consider various influencing factors and predict results quickly and accurately in an economic way. Moreover, their results have a wide 
applicability [30-32]. However, field operations show that these artificial intelligence technologies have some limitations. For example, some scholars have noted issues such as the excessive studying effect, as well as the requirement of a large number of computations and a lower speed of convergence than for the ANN model [1].

In undersea mining, continuous excavations will lead to unceasing fractures in the overlying rock strata. Once the WFZ connects with the sea water, an irreversible disaster will occur. To avoid this, it is necessary to retain a certain level of thickness in the roof pillar. However, a pillar that is too thick may lead to a waste of resources. If the pillar is too thin, the WFZ will easily connect with the sea water and cannot guarantee safety. Therefore, accurate analyses and predictions must be made for the height of the WFZ.

Unlike the aforementioned studies, a novel approach based on the RoF algorithm, which can generate base classifiers with large differences and a high precision, can improve the accuracy of prediction models for the height of the WFZ in undersea safety mining. The rotating forest (RoF) algorithm, proposed by Rodríguezin [33], is a new integrated learning algorithm. Compared with the random forest algorithm and other classical integrated learning algorithms, the RoF algorithm can generate base classifiers with large differences and a high precision, giving it a better generalization ability. RoF has been widely used in biomedicine [34], pattern recognition [35], geotechnical engineering [36], and environmental science [37]. In this study, the RoF algorithm is applied to estimate the development height of the WFZ in underwater mines.

\section{Methodology}

\subsection{Study Areas}

Due to the complexity of mining conditions and hydrogeological conditions, many mines in China are threatened by water, especially mines in the north of China. As shown in Figure 2, the provinces of Henan, Anhui, Shandong, and Shaanxi in China form a concentrated area in which mines are threatened by water. In order to ensure the economic development and survival of large populations, mines below rivers and lakes are being extracted. For example, the Beizao mine (No. 3 in Table 1), located in Shandong, is an undersea (Bohai Sea) mine. The No. H2106 working face in this mine is about $330 \mathrm{~m}$ deep, the working face length is $150 \mathrm{~m}$, the angle of the ore is $7^{\circ}$, and the height of the WFZ is $39 \mathrm{~m}$. This mine is threatened by seawater; once the WFZ is connected to the seawater, the results will be devastating to society. The Chenjiagou mine (No. 5 in Table 1), located in Liupan Mountain (the junction of Shaanxi, Gansu and Ningxia), is under the Beirui River. The No. H2106 working face in this mine is about $540 \mathrm{~m}$ deep, the working face length is $100 \mathrm{~m}$, the angle of the ore is $21^{\circ}$, and the height of the WFZ is $134 \mathrm{~m}$. To study the height of the WFZ with the RoF algorithm, large amounts of data on the WFZ must be gathered in these areas.

Table 1. Field-measured data for training and testing.

\begin{tabular}{ccccccc}
\hline No. & $\begin{array}{c}\text { Mining } \\
\text { Depth }(\mathbf{m})\end{array}$ & $\begin{array}{c}\text { Mining } \\
\text { Height }(\mathbf{m})\end{array}$ & $\begin{array}{c}\text { Lithology } \\
\text { Type }\end{array}$ & $\begin{array}{c}\text { Working-Face } \\
\text { Length }(\mathbf{m})\end{array}$ & $\begin{array}{c}\text { Dip Angle } \\
\left({ }^{\circ}\right)\end{array}$ & $\begin{array}{c}\text { Height of the } \\
\text { WFZ }(\mathbf{m})\end{array}$ \\
\hline 1 & 417 & 2.9 & 4 & 80 & 4 & 68 \\
2 & 350 & 8.5 & 3 & 169 & 6.5 & 55.255 \\
3 & 330 & 4.1 & 1 & 150 & 7 & 39 \\
4 & 150.4 & 2 & 4 & 174 & 23 & 58.4 \\
5 & 540 & 12.4 & 2 & 100 & 21 & 134 \\
6 & 49 & 4 & 1 & 135 & 5 & 45 \\
7 & 460 & 11.4 & 3 & 207 & 8 & 194.6 \\
8 & 510 & 7.5 & 3 & 195 & 6 & 185 \\
9 & 43 & 3 & 4 & 30 & 60 & 35 \\
10 & 600 & 8.78 & 3 & 223.35 & 6 & 54.08 \\
11 & 321 & 9 & 2 & 120 & 5 & 111 \\
12 & 420 & 3.4 & 3 & 70 & 23 & 56.8 \\
\hline
\end{tabular}


Table 1. Cont.

\begin{tabular}{|c|c|c|c|c|c|c|}
\hline No. & $\begin{array}{c}\text { Mining } \\
\text { Depth (m) }\end{array}$ & $\begin{array}{c}\text { Mining } \\
\text { Height (m) }\end{array}$ & $\begin{array}{l}\text { Lithology } \\
\text { Type }\end{array}$ & $\begin{array}{l}\text { Working-Face } \\
\text { Length }(\mathrm{m})\end{array}$ & $\begin{array}{c}\text { Dip Angle } \\
\left({ }^{\circ}\right)\end{array}$ & $\begin{array}{c}\text { Height of the } \\
\text { WFZ (m) }\end{array}$ \\
\hline 13 & 173 & 1.9 & 4 & 70 & 20 & 25.3 \\
\hline 14 & 173 & 2 & 3 & 70 & 20 & 26.7 \\
\hline 15 & 84 & 4 & 2 & 108 & 3 & 30 \\
\hline 16 & 300 & 4 & 2 & 75 & 2 & 120 \\
\hline 17 & 590 & 2.99 & 2 & 220 & 6 & 47.6 \\
\hline 18 & 620 & 3.1 & 4 & 240 & 3.5 & 20.215 \\
\hline 19 & 458 & 6 & 3 & 190 & 6 & 114.2 \\
\hline 20 & 404.5 & 2.3 & 3 & 95 & 18 & 19.5 \\
\hline 21 & 313.5 & 2.4 & 3 & 65 & 6 & 21.9 \\
\hline 22 & 480 & 6.3 & 3 & 170 & 4 & 46.13 \\
\hline 23 & 480 & 5.2 & 1 & 150 & 9 & 42.3 \\
\hline 24 & 200 & 8 & 4 & 89 & 76 & 48 \\
\hline 25 & 220 & 5.3 & 3 & 120 & 25 & 46.5 \\
\hline 26 & 89 & 2.03 & 4 & 69 & 7 & 45.86 \\
\hline 27 & 200 & 1.5 & 1 & 45 & 0 & 4.5 \\
\hline 28 & 284 & 7 & 2 & 130 & 3.5 & 26 \\
\hline 29 & 276 & 4.5 & 1 & 350 & 7 & 17.2 \\
\hline 30 & 350 & 2.5 & 2 & 135 & 5 & 20 \\
\hline 31 & 282 & 4 & 3 & 71 & 8 & 33 \\
\hline 32 & 240 & 3.5 & 1 & 195 & 7 & 21.675 \\
\hline 33 & 240 & 3.5 & 1 & 195 & 7 & 17.445 \\
\hline 34 & 368.05 & 5.77 & 3 & 125 & 6 & 48.35 \\
\hline 35 & 541.5 & 5.28 & 3 & 175 & 6.5 & 49.25 \\
\hline 36 & 340 & 1.8 & 2 & 178 & 3 & 19.69 \\
\hline 37 & 319 & 2 & 2 & 148 & 5 & 17.155 \\
\hline 38 & 311 & 2 & 2 & 85 & 3 & 19.11 \\
\hline 39 & 327.5 & 2 & 2 & 78 & 7 & 22.995 \\
\hline 40 & 355.5 & 2 & 2 & 125 & 3 & 23.865 \\
\hline 41 & 349 & 2 & 3 & 130 & 5.5 & 22.31 \\
\hline 42 & 363 & 2 & 3 & 180 & 8 & 16.845 \\
\hline 43 & 447 & 2 & 3 & 107 & 4 & 30.965 \\
\hline 44 & 420.5 & 2.8 & 3 & 135 & 3 & 41.13 \\
\hline 45 & 509.5 & 3 & 2 & 140 & 10 & 26.01 \\
\hline 46 & 383 & 2.2 & 2 & 125 & 5 & 13.035 \\
\hline 47 & 376.5 & 2 & 2 & 124 & 5 & 12.675 \\
\hline 48 & 391 & 1.8 & 2 & 125 & 5 & 14.29 \\
\hline 49 & 404 & 2.2 & 2 & 150 & 6 & 21.195 \\
\hline 50 & 415 & 3.4 & 3 & 120 & 8 & 30.085 \\
\hline 51 & 418 & 1.8 & 3 & 120 & 6 & 24.69 \\
\hline 52 & 550 & 5.8 & 1 & 180 & 8 & 65.2 \\
\hline 53 & 552.5 & 5.8 & 3 & 182 & 8 & 44.36 \\
\hline 54 & 490.5 & 6 & 3 & 182 & 7 & 44.19 \\
\hline 55 & 360 & 7.69 & 3 & 220 & 3 & 45.125 \\
\hline 56 & 117 & 3.4 & 2 & 205 & 2 & 72 \\
\hline 57 & 520 & 2.3 & 3 & 174 & 12 & 50.675 \\
\hline 58 & 509 & 2.25 & 3 & 180 & 12.5 & 34.925 \\
\hline 59 & 402.5 & 3 & 3 & 170 & 12 & 19.6 \\
\hline 60 & 550 & 2.4 & 4 & 180 & 15 & 55.32 \\
\hline 61 & 56 & 4.3 & 4 & 55 & 0 & 42.5 \\
\hline 62 & 395.5 & 3.45 & 3 & 160 & 14 & 26.7 \\
\hline 63 & 446 & 3.8 & 4 & 143 & 17 & 40 \\
\hline 64 & 100 & 3.4 & 3 & 80 & 6 & 44.4 \\
\hline 65 & 230 & 2 & 1 & 85 & 37 & 52.5 \\
\hline 66 & 384.2 & 2.65 & 3 & 190.5 & 21 & 33 \\
\hline 67 & 306 & 3 & 3 & 150 & 28 & 33.615 \\
\hline 68 & 460 & 12.4 & 3 & 227 & 12 & 30 \\
\hline 69 & 125 & 3 & 1 & 150 & 5 & 22 \\
\hline
\end{tabular}


Table 1. Cont.

\begin{tabular}{|c|c|c|c|c|c|c|}
\hline No. & $\begin{array}{c}\text { Mining } \\
\text { Depth (m) }\end{array}$ & $\begin{array}{c}\text { Mining } \\
\text { Height (m) }\end{array}$ & $\begin{array}{c}\text { Lithology } \\
\text { Type }\end{array}$ & $\begin{array}{l}\text { Working-Face } \\
\text { Length (m) }\end{array}$ & $\begin{array}{c}\text { Dip Angle } \\
\left({ }^{\circ}\right)\end{array}$ & $\begin{array}{c}\text { Height of the } \\
\text { WFZ (m) }\end{array}$ \\
\hline 70 & 474.16 & 5.8 & 3 & 230 & 4 & 65.395 \\
\hline 71 & 316 & 5.9 & 3 & 248 & 4.5 & 114.7 \\
\hline 72 & 316 & 5.2 & 3 & 248 & 4.5 & 102.3 \\
\hline 73 & 386.5 & 3.1 & 3 & 150 & 10 & 40.79 \\
\hline 74 & 380 & 3.5 & 3 & 180 & 6 & 45.84 \\
\hline 75 & 101.1 & 2.2 & 3 & 158 & 1 & 63 \\
\hline 76 & 290 & 6 & 1 & 645 & 8 & 85.6 \\
\hline 77 & 325 & 8 & 2 & 134 & 8 & 83.9 \\
\hline 78 & 255 & 4.2 & 2 & 72 & 18 & 51.3 \\
\hline 79 & 450 & 8 & 4 & 170 & 8 & 86.8 \\
\hline 80 & 412 & 6.9 & 3 & 160 & 4 & 38.8 \\
\hline 81 & 332.85 & 7.15 & 3 & 160 & 5 & 16.115 \\
\hline 82 & 319.2 & 8.2 & 3 & 160 & 7.5 & 27.84 \\
\hline 83 & 278.15 & 8.7 & 3 & 170 & 8 & 28.56 \\
\hline 84 & 282 & 8.55 & 3 & 140 & 5 & 25.255 \\
\hline 85 & 258.55 & 8.45 & 3 & 175 & 3 & 20.85 \\
\hline 86 & 286.45 & 7.8 & 3 & 150 & 8 & 35.9 \\
\hline 87 & 395 & 2.5 & 3 & 178 & 9 & 26.33 \\
\hline 88 & 478.5 & 2.5 & 3 & 180 & 8 & 33.755 \\
\hline 89 & 445 & 4 & 3 & 198 & 8 & 29.265 \\
\hline 90 & 490.5 & 5 & 3 & 172 & 8 & 52.76 \\
\hline 91 & 490 & 6 & 1 & 182 & 8 & 67.8 \\
\hline 92 & 640 & 8.5 & 3 & 232 & 6.5 & 193.4 \\
\hline 93 & 580 & 10.7 & 3 & 150 & 7.5 & 227.7 \\
\hline 94 & 347 & 9.9 & 3 & 100 & 2 & 79.255 \\
\hline 95 & 320 & 1.7 & 4 & 65 & 6 & 27.5 \\
\hline 96 & 187.5 & 1.2 & 3 & 300 & 10 & 10.41 \\
\hline 97 & 450 & 5.5 & 2 & 300 & 5 & 61 \\
\hline 98 & 342.5 & 3.8 & 3 & 114 & 13 & 28.455 \\
\hline 99 & 338.5 & 1.9 & 3 & 115.5 & 20 & 20.995 \\
\hline 100 & 316 & 1.9 & 3 & 165 & 12 & 26.085 \\
\hline 101 & 296 & 1.9 & 4 & 95.5 & 15 & 17.84 \\
\hline 102 & 493.75 & 13.43 & 3 & 130 & 15 & 93.175 \\
\hline 103 & 120 & 1.2 & 2 & 75 & 8 & 31 \\
\hline 104 & 605.5 & 3 & 3 & 136 & 2 & 38.185 \\
\hline 105 & 516 & 3.9 & 3 & 205 & 2 & 31.765 \\
\hline 106 & 520.5 & 3 & 3 & 202 & 2 & 33.365 \\
\hline 107 & 960 & 6 & 2 & 190 & 5 & 65.4 \\
\hline
\end{tabular}

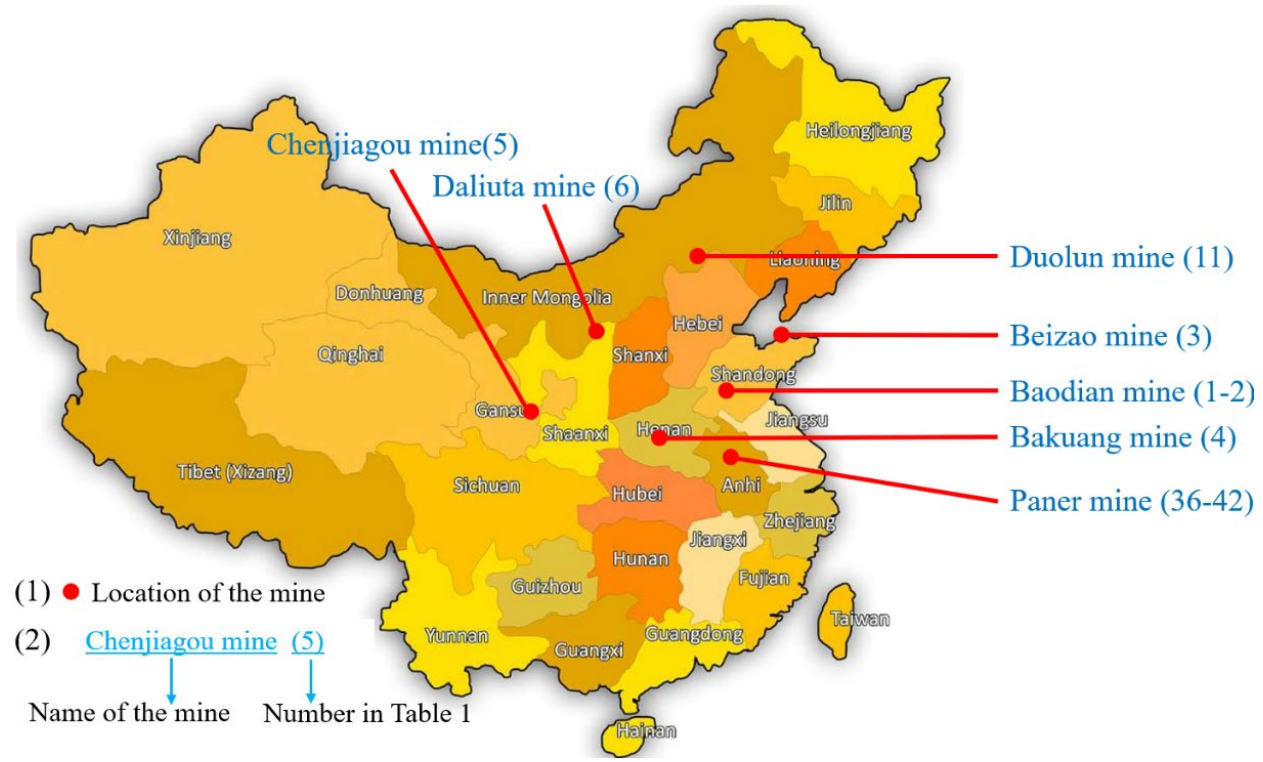

Figure 2. Mines threatened by water in China (partially described in Table 1). 


\subsection{Data Collection}

In this study, 107 cases were collected from several mines in China [38-43]. Each data group contains field-measured data on the height of the WFZ and the aforementioned five main controlling factors, which are shown in Table 1. According to the literature, the lithological types of the rocks in these mines can possess different grades, subject to the uniaxial compressive strength of the rock. A value of 1 means that the rock is soft, a value of 2 means that the rock is medium soft, a value of 3 means that the rock is medium hard, and a value of 4 means that the rock is hard.

\subsection{Rotating Forest Algorithm}

The RoF ensemble algorithm can process the original sample features and use a certain feature transformation method to obtain the different sample sets required by the training base classifier. After that, the differences between the individual classifiers can be obtained. Then, the purpose of improving the classification accuracy rate can be achieved. This procedure is shown in Figure 3.

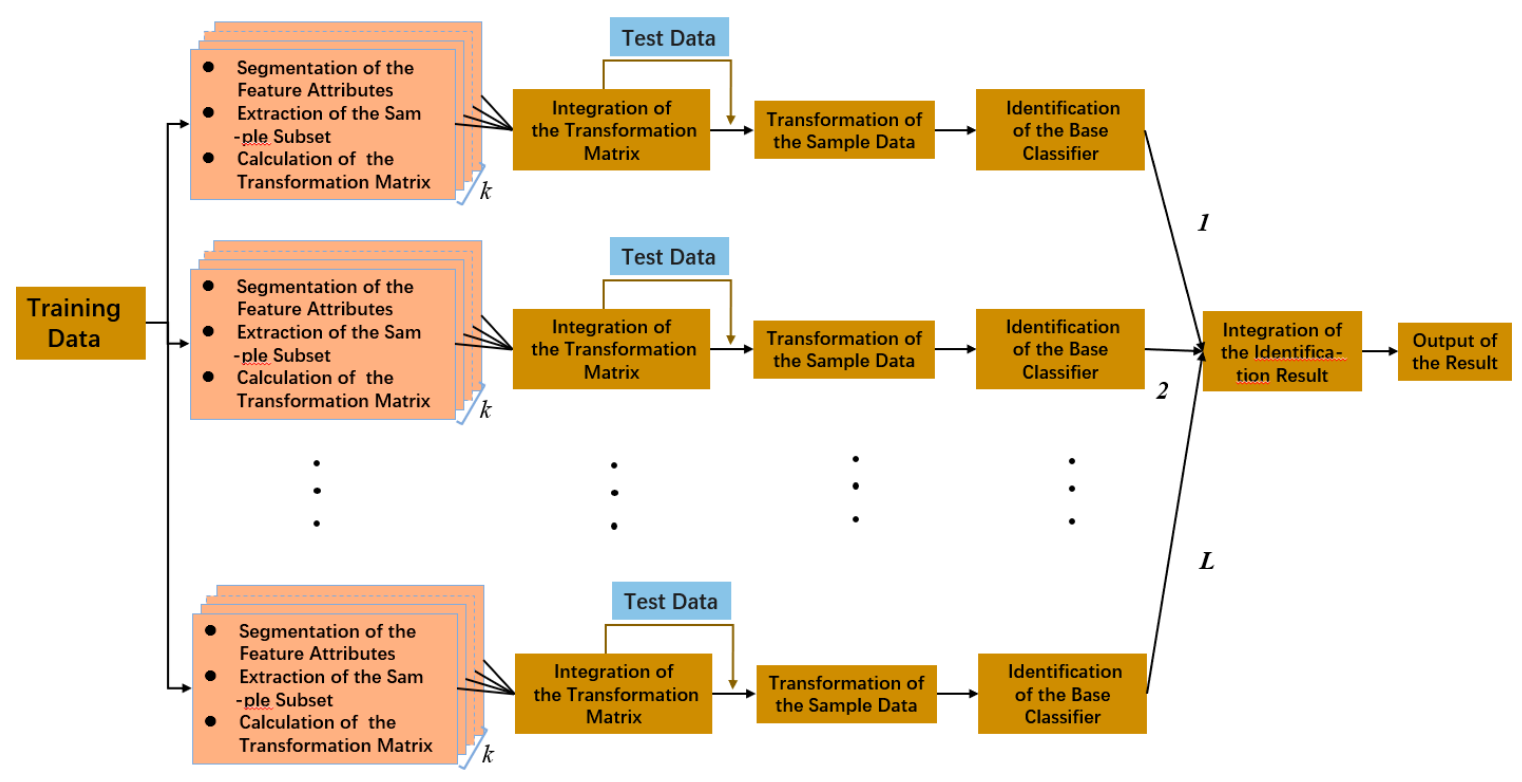

Figure 3. The procedure of the RoF (rotating forest) algorithm.

First, the training dataset can be defined as follows:

$$
\begin{aligned}
& D=\{X, Y\}=\left\{\left(x_{1}, y_{1}\right),\left(x_{2}, y_{2}\right), \ldots,\left(x_{n}, y_{n}\right)\right\} \\
& x_{i} \in R^{P}-\text { the input of the training set } \\
& y_{i} \in\left\{C_{1}, C_{2}, \ldots, C_{m}\right\}-\text { the output of the training } \\
& F-\text { the feature set of } D \text { (the training set). }
\end{aligned}
$$

Second, the parameters in the RoF algorithm need to be defined in advance-namely $s$ (the feature number of subsets) and $\boldsymbol{L}$ (the scale of integration). Among the parameters, $s$ represents the number of characteristic indexes included in each feature subset, and $L$ represents the number of base classifiers included in the integrated system. The RoF calculation process can be divided into two stages: the generation and synthesis of the base classifier.

Stage 1: Generation of the base classifier

(1) The original feature set can be randomly segmented, and each subset contains $a$ number of characteristic indexes. Among these subsets, any two subsets cannot intersect. If the original feature set is indivisible, then the remainder forms a subset. In the end, a number of subsets can be obtained. The $j$-th feature subset of the $i$-th base classifier $\left(F_{i j}\right)$ can then be expressed. 
(2) All $F_{i j}$ samples are extracted from the dataset $X$, and $75 \%$ of the samples are randomly extracted with the bootstrap method to generate the sample subset $X_{i j}$. The subset $X_{i j}$ can be transformed into $W_{i j}$ according to the feature transformation algorithm. The transformed matrix $W_{i 1}, W_{i 2}, \cdots, W_{i k}$ can be arranged to generate a sparse matrix $W_{i}$, which is defined as follows:

$$
W_{i}=\left[\begin{array}{ccc}
W_{i 1} & \ldots & 0 \\
\vdots & \ddots & 0 \\
0 & \ldots & W_{i k}
\end{array}\right]
$$

(3) The matrix $W_{i}$ can be adjusted to obtain the new matrix $W_{i}^{*}$, and each column is consistent with the original feature set sequence.

(4) Using $\left\{X W_{i}^{*}, Y\right\}$ as the training set, the decision tree algorithm can be used to train the $i$-th base classifier, which is named $G_{i}$. Steps (1)-(3) are repeated until the $L$ base classifiers of $G_{1}, G_{2}, \cdots, G_{L}$ are trained and generated. During the generation of the base classifier, the rotation transformation matrix $W_{i}^{*}$ and its corresponding base classifier $G_{i}$ can be recorded to direct the subsequent synthesis of the base classifier.

Stage 2: Generation and synthesis of the base classifier

(5) Rotate the new sample $x$, which can obtain $x^{\prime}{ }_{i}=x W_{i}{ }_{i}^{*}$.

(6) Use the base classifier $G_{i}$ to predict $x \prime_{i}$.

(7) Repeat steps (5) and (6), and the classification results of all base classifiers can be obtained. Then, the results can be integrated as per the following equation:

$$
u_{j}(x)=\frac{1}{L} \sum_{i=1}^{L} P_{j}\left(x_{i}^{\prime}\right), j=1,2, \cdots, m .
$$

(8) Place sample $x$ into the category with the highest probability; then, the final integrated classification result can be obtained.

\subsection{Feature Transformation Algorithm}

The decision tree is a sensitive classifier, and any small change in the data may result in a completely different structure of the decision tree in training [44]. Therefore, the feature transformation algorithm plays a crucial role in constructing discrepant data and directly affects the final classification results. Based on high-order statistics, the multifeature data can be processed with Independent Component Analysis (ICA). ICA can transform the features of a dataset into several statistically independent feature combinations to ensure the high-order statistical properties of the dataset. ICA is regarded as an important extension of PCA and is also suitable as a feature change method for RoF. ICA has the following advantages: This approach can provide a more realistic statistical model, which can precisely determine the data at positions in a high-dimensional space. This method also provides a nonorthogonal basis space, which can better reconstruct the data information when the original dataset has outliers. Moreover, ICA is sensitive to high-order statistical information.

We assume that $\boldsymbol{X}$ (the s-dimensional random variable) is a linear combination of random variables $S$, whose s-dimension components are independent of each other and can be expressed as follows: $X=S A$. Then, the s-dimension matrix $W$ can be obtained, i.e., $U=X W$, where $U$ represents the $\mathrm{s}$-dimension matrix and is the estimated value of $S$, which satisfies the independence requirements of the s-dimensional components. Currently, the estimation algorithms of the matrix include fast ICA, Info Max, JADE, and radical ICA. 


\subsection{Model Evaluation Metrics}

Before the model is used for prediction, the accuracy of the model must be evaluated. The root mean square error (RMSE) and coefficient of determination $\left(R^{2}\right)$ can be selected as the evaluation indicators. These two indexes are defined as follows:

$$
\begin{gathered}
R M S E=\sqrt{\frac{1}{n} \sum_{i=1}^{n}\left(y_{i}-\hat{y}_{i}\right)^{2}}, \\
R^{2}=1-\frac{\sum_{i=1}^{n}\left(y_{i}-\hat{y}_{i}\right)^{2}}{\sum_{i=1}^{n}\left(y_{i}-\bar{y}_{i}\right)^{2}}
\end{gathered}
$$

where $\mathrm{n}$ - the total number of test datas

$\mathrm{y}_{\mathrm{i}}$ - the observed output value of the test sample

$y_{i}$ - the predicted value by the model

$\hat{y}_{i}$ - the average output value of the test samples.

\subsection{Controlling Factors of WFZ}

The WFZ is a complex phenomenon influenced by many factors [39]. In this study, according to the studies in [45-47], the indicators with major influencing factors on undersea safety mining were determined. Detailed descriptions of these five factors are provided below.

(1) Mining Depth

Geostress increases by increasing the mining depth. After the orebody is mined out, the lateral and vertical movements of the overlying strata lead to the formation of overburden mining fractures in the rock. Therefore, the deeper the mining depth of the underwater mining becomes, the higher the pressure of the overlying strata will be, the more intense the lateral and vertical movements of the rock strata will be, and the more fractures will occur in the rock.

\section{(2) Mining Height}

The mining height plays a key role in the stability of the overburden and the height of the broken rock. In a way, the mining height restricts the mine's size. At a certain recovery rate, the larger the mining height is, the larger the goaf will be. When the exposed space increases, the height of the overburden strata will also increase. If the mining height shows a growth trend, then the height of the overburden collapse will also exhibit a growth trend.

(3) Lithology Type

Under normal circumstances, due to the differences in plasticity, stiffness, brittleness, and other characteristics of the rock formation, the lithology will have correspondingly different impacts on the extent of the rock fracturing. If the lithology hardness is high, a more serious overburden damage development will occur than under a low lithology hardness, which will yield an only slight overburden damage development. For example, the fracture zone usually has fractures along the vertical or near-vertical plane. The question of whether the rock layer can be fractured, along with the degree of fracture development, are both directly related to the lithology.

\section{(4) Working-Face Length}

As the length of the face increases, a greater elastic potential will be released when the surrounding rock is damaged. Naturally, this will also cause a wider range of surrounding rock damage, and the extent of this damage is likely to increase with an increase in the working-face length. If an ore body with a constant thickness is mined, the size of the stope will also have different effects on the height of the overburden. The smaller the stope required for the mining method used, the lower the disturbance 
to the surrounding rock; and the lower the elastic strain energy released when the surrounding rock is destroyed, the smaller the generated damage height. Conversely, if a different mining method is applied, the larger the mine size required for the method is, the more damage it will cause.

(5) Orebody Dip Angle

In general, the inclination of an inclined orebody is inversely proportional to the height of the caving zone and the fracture zone, as shown in Figure 4. The inclination of the orebody will have a crucial influence on the height of the fractures in the overburden during mining. The upper and lower arch angles of the roof damage are small, but the upper arch angle is the largest. Due to the increase in this angle, the funnel of the roof damage will be reduced. At the same time, the corner of the arch will slowly disappear.
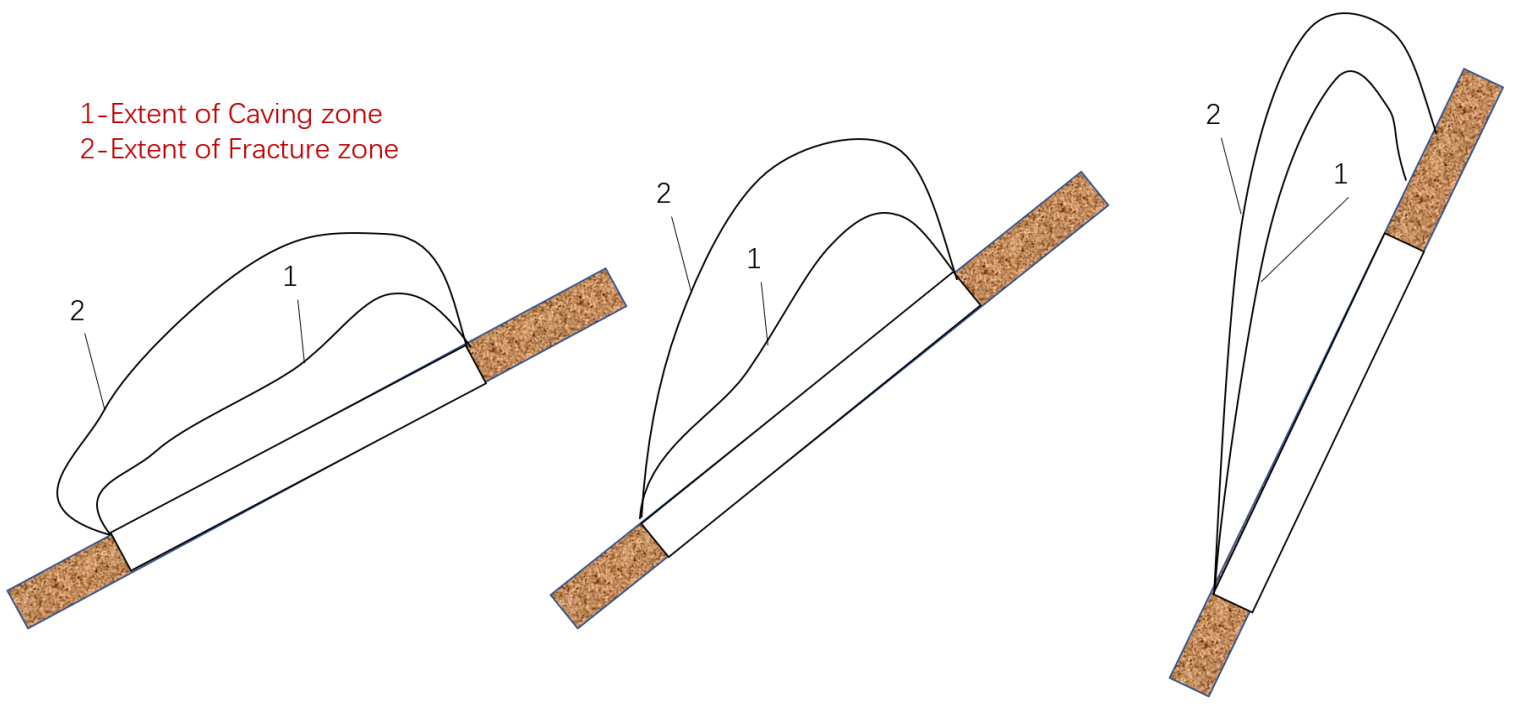

Figure 4. The extent of the WFZ in the inclined orebody.

\subsection{Shortcomings and Uncertainty}

Compared with the random forest algorithm and other classical integrated learning algorithms, the RoF algorithm can generate base classifiers with large differences and a high precision, thus giving it a better generalization ability. However, mining is a complicated industry affected by hydrogeological conditions. The uncertainty in this research lies in the absence of data on the fault, initial fissure, and pore water pressure in the rockmass. Unlike the five factors in Section 2.6, these data are difficult to obtain, analyze, and quantify. If these indicators experience a large change in the same mine, a more obvious difference could appear in the height of the WFZ, which could threaten the safety of the mine. In order to apply this method accurately, the hydrogeological conditions must be precisely detected.

In order to prevent the movement and fracture of the rock strata, progressively more mines are adopting the cut and fill mining method. The shortcomings in this research lie in the absence of influence from filling. The effects from filling on the fractures in rockmasses are very complex, and the filling materials' strength, filling rate, and compression rate may generate only a slight effect on the height of the WFZ. Future work will consider the effect of filling on the height of the WFZ.

\section{Results and Discussion}

\subsection{Validity Verification of RoF Model: Comparison and Evaluation}

Among the collected cases, we selected 75 (70\%) cases as a training dataset randomly and selected $32(30 \%)$ cases for testing the dataset. 
RMSE and $\mathrm{R}^{2}$ were selected to evaluate the three models. Based on Equations (4) and (5), the RMSE and $\mathrm{R}^{2}$ of each model was calculated, as indicated in Table 2. As shown, the RoF model has the lowest $\mathrm{R}^{2}$ value with 0.02 (compared to 0.08 for the RFR model and 0.13 for the SVM model) and a medium RMSE value of 39.81. Therefore, it can be concluded that the three models are reasonable, and that the RoF model has a better performance than the other two models.

Table 2. RMSE and $\mathrm{R}^{2}$ of the three models.

\begin{tabular}{ccc}
\hline Methods & RMSE (m) & $\mathbf{R}^{\mathbf{2}}$ \\
\hline Random forest & 37.75 & 0.972 \\
SVM & 41.30 & 0.902 \\
Rotation forest & 39.81 & 0.968 \\
\hline
\end{tabular}

Figure 5 shows the comparison of the observed and predicted heights determined using the three models. Compared with the RFR and SVM models, the data predicted by the RoF model are almost the same as those predicted with the measured data, while the results predicted by the other two models are slightly different from the measured data.

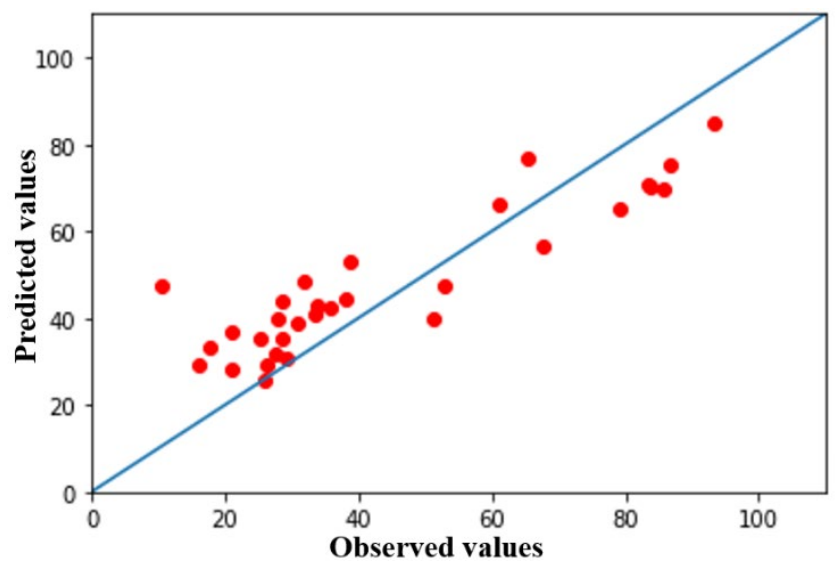

(a)

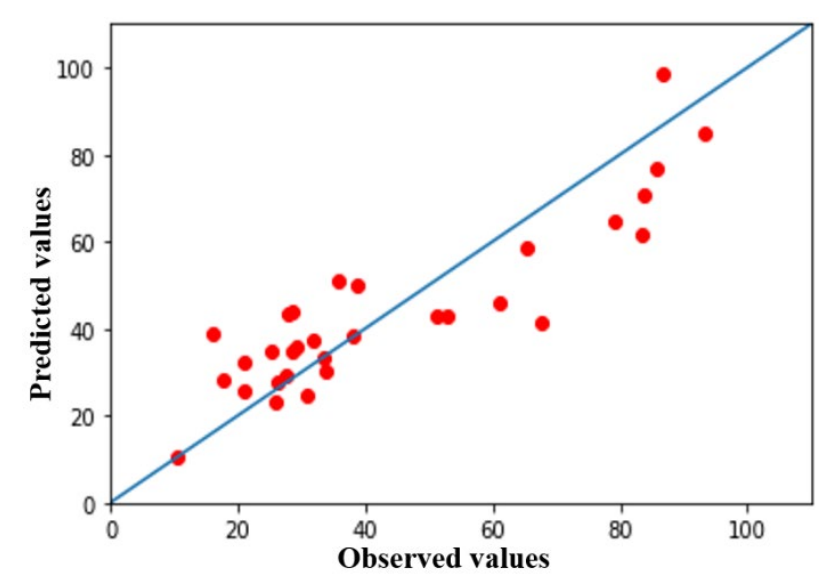

(b)

Figure 5. Cont. 


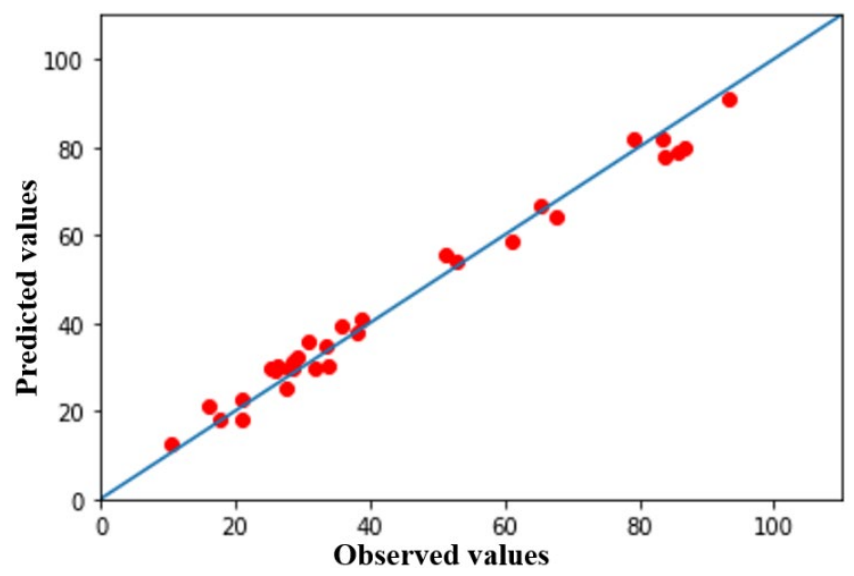

(c)

Figure 5. A comparison of the observed and predicted heights based on the test data using (a) SVM (Support Vector Machine), (b) RFR (Random Forest), and (c) RoF.

Figures 6-8 reveal that the contributions of the five factors in each model can be obtained. As shown, the importance degree of each factor is measured in two ways: the mean decrease in the Gini index and the OOB mean decrease in accuracy.

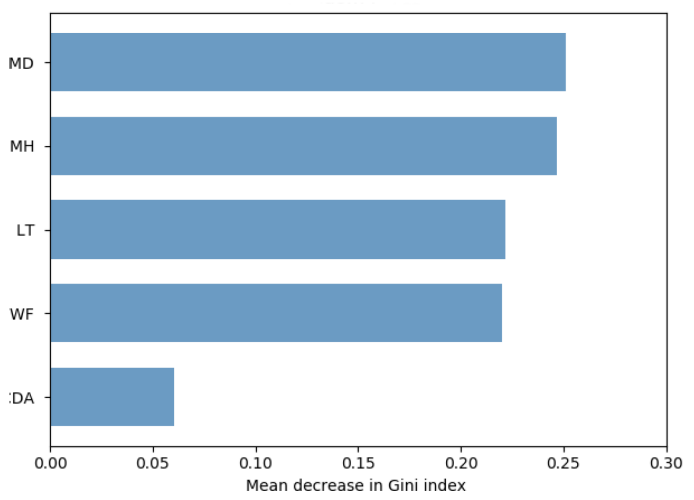

(a)

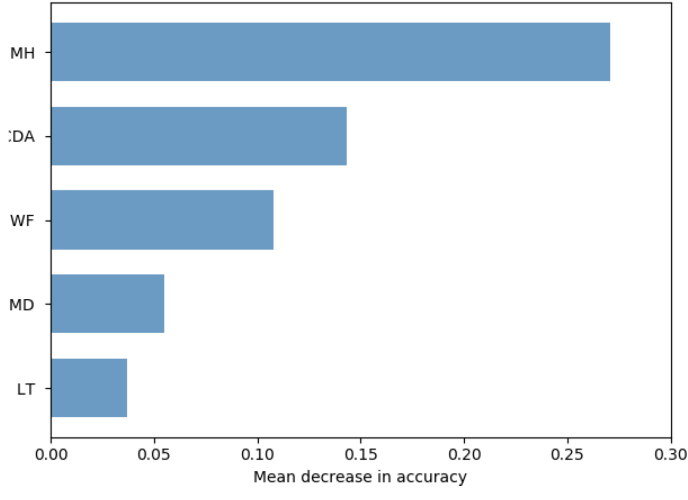

(b)

Figure 6. The importance degree of the main controlling factors in SVM: (a) the mean decrease in the Gini index; (b) the mean decrease in accuracy.

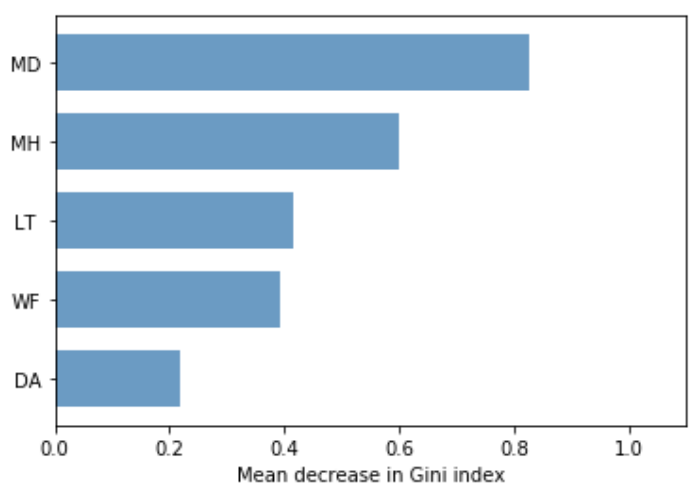

(a)

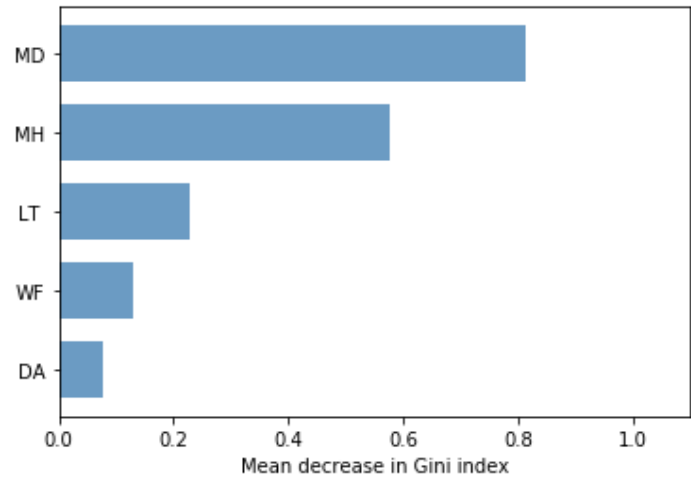

(b)

Figure 7. The importance degree of the main controlling factors in RFR: (a) the mean decrease in the Gini index; (b) the mean decrease in accuracy. 


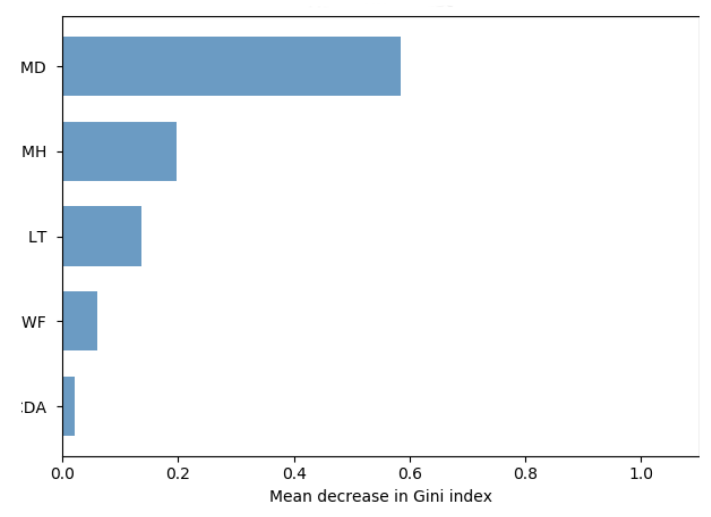

(a)

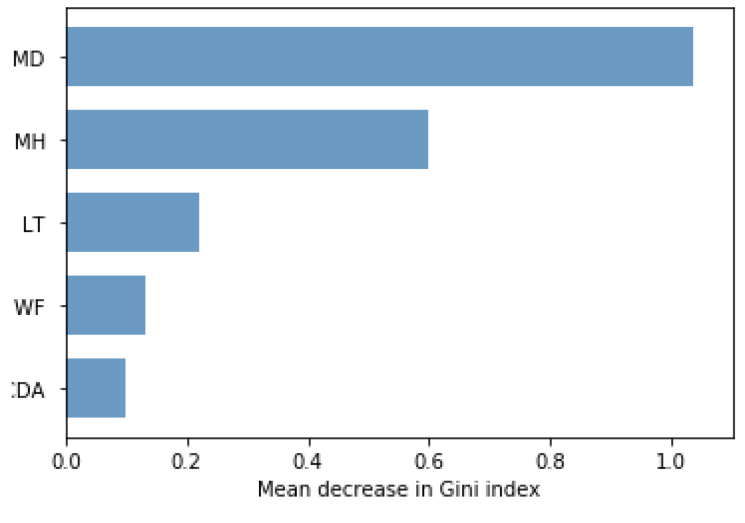

(b)

Figure 8. The importance degree of the main controlling factors in RoF: (a) the mean decrease in the Gini index; (b) the mean decrease in accuracy.

In the RoF model, the mining height and mining depth have the highest importance, followed by the lithology type and working-face length. The dip angle has the lowest importance in the Gini index. Regarding the mean decrease in accuracy, the order of the importance degree is consistent with the results obtained for the Gini index method.

Compared with the SVM and RFR models, the mining height and mining depth have the highest importance in the RoF model, followed by the lithology type and working-face length. The dip angle has the lowest importance in the Gini index. Regarding the mean decrease in accuracy, the order of the importance degree is consistent with the results obtained for the Gini index method.

\subsection{Engineering Application}

\subsubsection{Project Profile}

The Xinli mining area is located to the southwest of the Sanshandao gold mine in Shandong Province, China. The designed production capacity of the Xinli mining district is $1500 \mathrm{t} /$ day. It is the largest undersea metal mine in the world thus far.

Geographically, the Xinli mining district is located at the intersection of Bohai Bay and the Wanghe River. Bohai Bay is located on the west and north sides of the mining area, as shown in Figure 9. The entire coastline is nearly $5000 \mathrm{~km}$ long. The south side is the coastal plain, and the east side is the Wanghe River. There is also a surface industrial plant on the coastal plain. Because it is located at the intersection of Bohai Bay and the Wanghe River, the surface water in the area is derived from these water bodies. The orebody is basically under the Wanghe River and Bohai Bay, and the main ore body is at an angle of $60^{\circ}$ with the coastline, while the ore dip angle is $46^{\circ}$. From the perspective of the relationship between the water bodies, the safety of the Xinli mining district is largely affected by seawater. The test results of the hydrogeological conditions and lithological parameters in the mining area show that the hard rock composed of fricrock and siltstone is an aquifer with a cumulative thickness of about $30 \mathrm{~m}$. The geological well off the coast of Xinli can illustrate the stratum's structure, as shown in Figure 10.

To prevent water inrush disasters, it is important to accurately determine the height of the WFZ in the mining-disturbed overburden. 


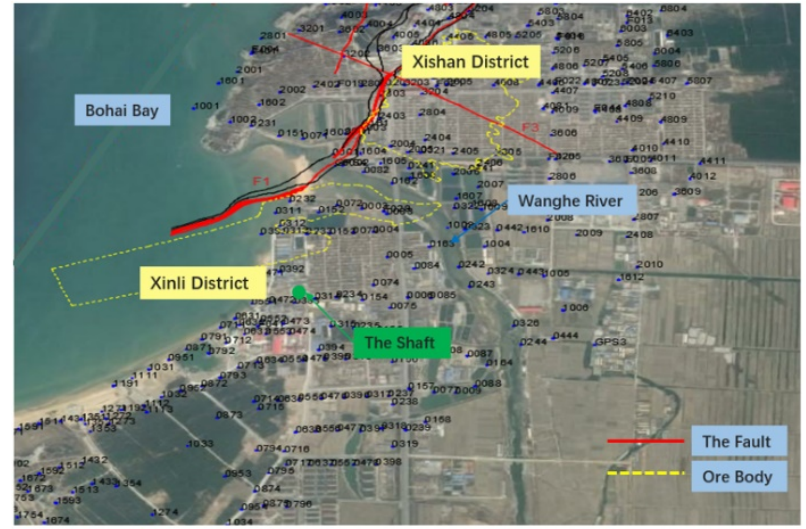

(a)

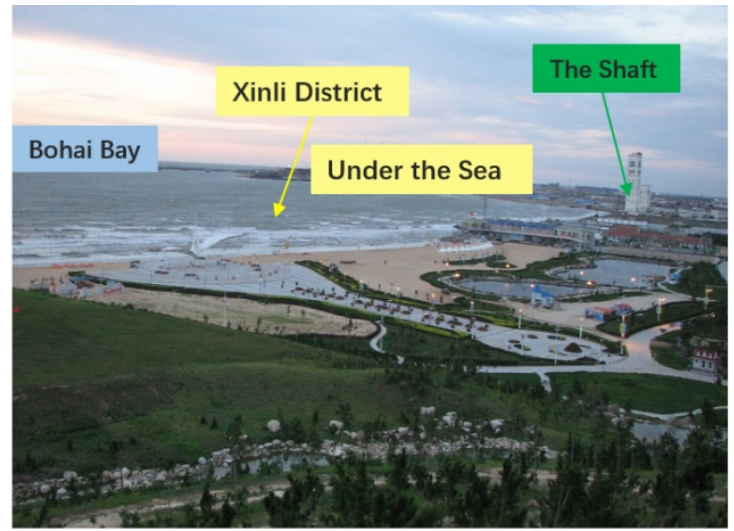

(b)

Figure 9. The location of the Xinli District: (a) Geographical position of the Sanshandao Gold Mine; (b) Geographical position of the Xinli District.

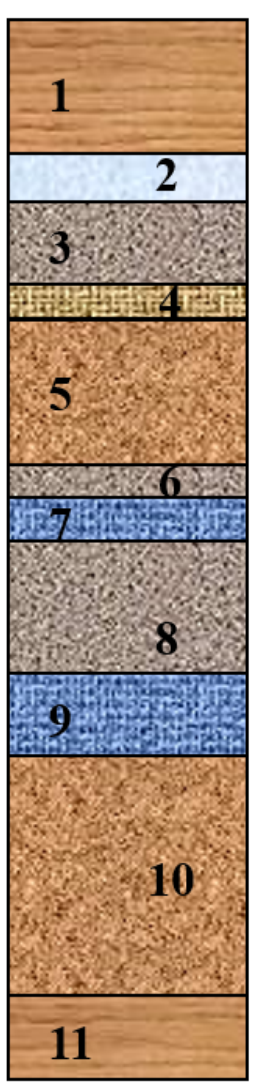

\begin{tabular}{|c|c|c|c|}
\hline No. & Lithology & Thickness/m & Depth/m \\
\hline 1 & Weathered sandstone & 4.2 & 4.2 \\
\hline 2 & Gritrock & 1.0 & 5.2 \\
\hline 3 & $\begin{array}{l}\text { Mud-sandstone } \\
\text { interbedded }\end{array}$ & 2.3 & 7.5 \\
\hline 4 & Mud-sandstone & 1.1 & 8.6 \\
\hline 5 & Siltstone & 4.1 & 12.7 \\
\hline 6 & $\begin{array}{l}\text { Mud-sandstone } \\
\text { interbedded }\end{array}$ & 0.8 & 13.5 \\
\hline 7 & Medium sandstone & 1.2 & 14.7 \\
\hline 8 & $\begin{array}{l}\text { Mud-sandstone } \\
\text { interbedded }\end{array}$ & 3.8 & 18.5 \\
\hline 9 & Medium sandstone & 2.2 & 20.7 \\
\hline 10 & Siltstone & 6.9 & 27.6 \\
\hline 11 & Weathered sandstone & 2.4 & 30 \\
\hline
\end{tabular}

Figure 10. Stratigraphic column of the geologic well in the Xinli District.

\subsubsection{Prediction the Height of the Water-Flow Fracture Zone}

In the Xinli district, the classification of the lithology type is 2, the orebody dip angle is $46^{\circ}$, the mining heights at each depth are $35 \mathrm{~m}, 40 \mathrm{~m}$, and $40 \mathrm{~m}$, and the working-face lengths at each depth are $49 \mathrm{~m}, 56 \mathrm{~m}$, and $56 \mathrm{~m}$. By applying the SVM, RFR, and RoF models generated above the stratum fractures during excavation at $-165 \mathrm{~m},-200 \mathrm{~m}$, and $-240 \mathrm{~m}$ depths, the height of the WFZ can be predicted, as listed in Table 3. 
Table 3. Predicting the height of the WFZ with the three models at the three depths.

\begin{tabular}{ccccccc}
\hline Methods & $\begin{array}{c}\text { Mining } \\
\text { Depth }(\mathbf{m})\end{array}$ & $\begin{array}{c}\text { Mining } \\
\text { Height }(\mathbf{m})\end{array}$ & $\begin{array}{c}\text { Lithology } \\
\text { Type }\end{array}$ & $\begin{array}{c}\text { Working-Face } \\
\text { Length }(\mathbf{m})\end{array}$ & $\begin{array}{c}\text { Dip Angle } \\
\left({ }^{\circ}\right)\end{array}$ & $\begin{array}{c}\text { Predicted } \\
\text { Result (m) }\end{array}$ \\
\hline \multirow{2}{*}{ Rotation } & -165 & 35 & 2 & 49 & 46 & 38.65 \\
Forest & -200 & 40 & 2 & 56 & 46 & 33.35 \\
& -240 & 40 & 2 & 56 & 46 & 36.56 \\
\hline \multirow{2}{*}{ Random } & -165 & 35 & 2 & 49 & 46 & 36.65 \\
Forest & -200 & 40 & 2 & 56 & 46 & 28.33 \\
& -240 & 40 & 2 & 56 & 46 & 32.24 \\
\hline \multirow{2}{*}{ SVM } & -165 & 35 & 2 & 49 & 46 & 35.15 \\
& -200 & 40 & 2 & 56 & 46 & 24.15 \\
& -240 & 40 & 2 & 56 & 46 & 29.64 \\
\hline
\end{tabular}

\subsubsection{Field Observation}

To verify the accuracy of the predicted values, a panoramic borehole televiewer (Figure 11) was employed to measure the height of the WFZ at each depth. The televiewer can present a clear visual inspection of the rocks along the borehole wall with $360^{\circ}$ borehole images and real-time videos. This device can thus record the characteristics of the fractures above the caved zone.

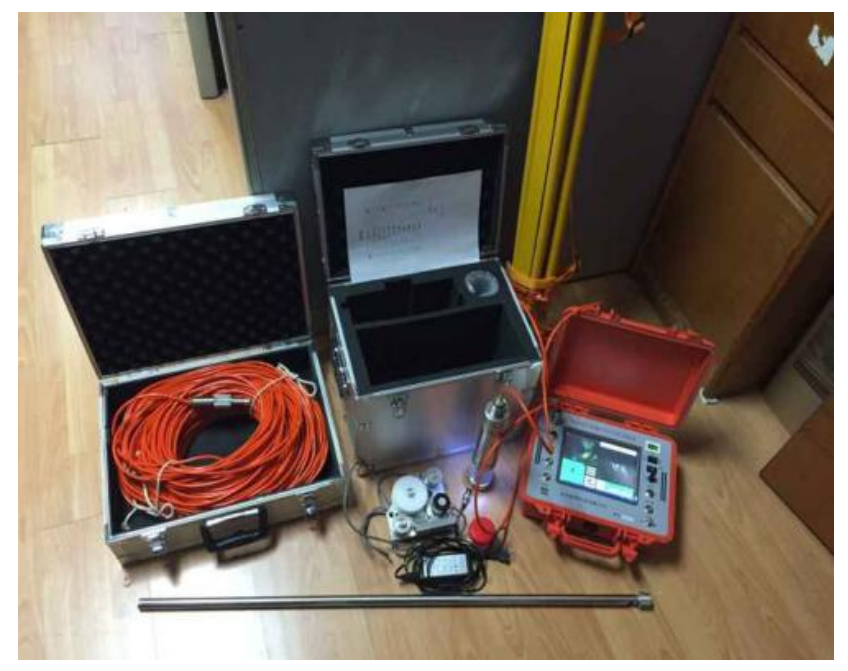

Figure 11. The GD3Q-GA panoramic borehole televiewer.

The aperture, interconnectivity, fracture development degree, and even traces of the flow of water can be observed by increasing the borehole depth. Furthermore, the top boundaries of the fractured zone above the caved zone can be determined by this device. To obtain the height of the WFZ at the top of the Xinli District, four boreholes were drilled along the roadway to a $-200 \mathrm{~m}$ depth to measure the height of the WFZ at a $-240 \mathrm{~m}$ depth. The height of the WFZ at $-200 \mathrm{~m}$ and $-165 \mathrm{~m}$ depths was measured by Chen in $[17,45]$.

In borehole (1), the developed fractures above $33.64 \mathrm{~m}$ had relatively large apertures and tended to be interconnected; water flow traces were also clearly visible, as shown in Figure 12a. However, the fractures in the lower region were isolated, and the apertures were relatively small. In boreholes (2) to (4), similar separations were located at $34.18 \mathrm{~m}, 35.28 \mathrm{~m}$, and $31.58 \mathrm{~m}$ from the bottom of the hole. Based on these data, the height of the WFZ at a $-240 \mathrm{~m}$ depth could be determined. It is reasonable to infer that the height of the WFZ at a $-240 \mathrm{~m}$ depth is approximately $35.3 \mathrm{~m}$. 

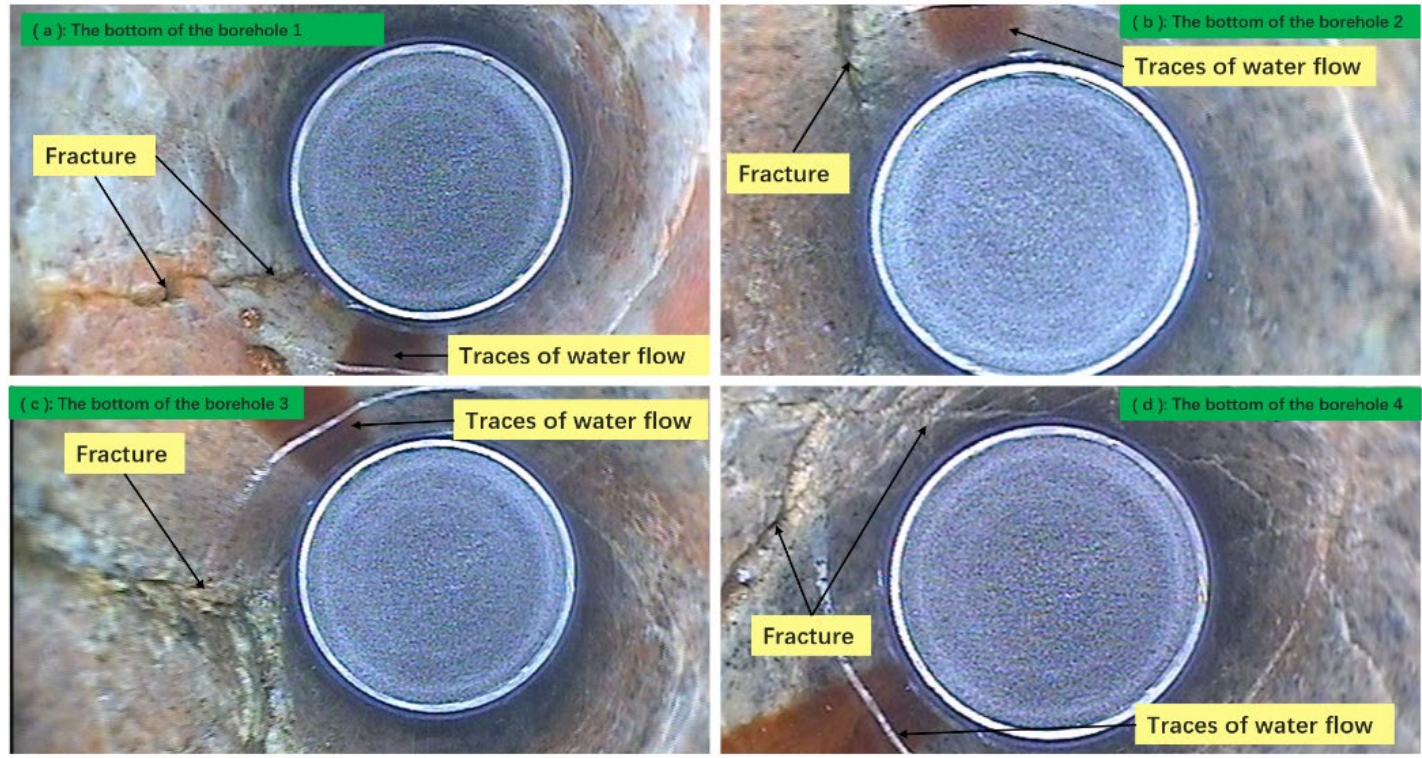

Figure 12. Images of the borehole.

A comparison between the field observation data and the prediction results obtained via the three models is summarized in Table 4. The field observations at $-165 \mathrm{~m}$ and $-200 \mathrm{~m}$ from $[17,45]$ are included in this table. Compared with the field-measured data, the average relative errors are $2.87 \%$, $8.72 \%$, and $16.8 \%$, which indicates that the RoF model has the best application performance.

Table 4. A comparison between the three models and the field observations at the three depths.

\begin{tabular}{cccccc}
\hline Methods & Depth $(\mathbf{m})$ & $\begin{array}{c}\text { Field } \\
\text { Observation }(\mathbf{m})\end{array}$ & $\begin{array}{c}\text { Predicted } \\
\text { Result (m) }\end{array}$ & $\begin{array}{c}\text { Absolute } \\
\text { Error (m) }\end{array}$ & $\begin{array}{c}\text { Relative } \\
\text { Error (\%) }\end{array}$ \\
\hline \multirow{3}{*}{ Rotation Forest } & -165 & 40.5 & 38.65 & 0.35 & 0.90 \\
& -200 & 32.1 & 33.35 & 1.35 & 4.21 \\
& -240 & 35.3 & 36.56 & 1.26 & 3.50 \\
\hline \multirow{3}{*}{ Random Forest } & -165 & 40.5 & 36.65 & 2.35 & 6.03 \\
& -200 & 32.1 & 28.33 & 3.67 & 11.47 \\
\hline \multirow{2}{*}{ SVM } & -240 & 35.3 & 32.24 & 3.06 & 8.67 \\
\hline
\end{tabular}

\section{Conclusions}

Owing to its unique hydrogeological environment, undersea mining is a special type of metal mining with high risk. In this study, a novel approach based on the RoF algorithm was proposed to predict the height of the WFZ. To train and test the model, 107 data were collected, and five main controlling factors were employed. Furthermore, the trained and tested model was used to predict the height of the WFZ at a $-240 \mathrm{~m}$ depth in undersea mining. Compared with other classical integrated learning algorithms, the RoF algorithm can generate base classifiers with large differences and a high precision, giving it a better generalization ability and the smallest $R^{2}$ value. To verify the accuracy of the predicted value, a panoramic borehole televiewer was employed to measure the height of the WFZ at each depth. The result indicates that the RoF model has the smallest relative error and best application performance.

Compared with other models, the WFZ development height prediction model based on the RoF algorithm has the following advantages: (1) The model has the features of simple data processing and 
good compatibility for new data, and it is conducive to the expansion of the database; (2) The model has a high recognition accuracy, good generalization ability, and more reliable mapping; (3) As a base classifier, the decision tree can deal with continuous variables and type variables, while also being less affected by outliers. At the same time, the model also has inevitable shortcomings: For unbalanced data sets, the recognition results of the RoF algorithm are more inclined toward more categories. In general, it is completely feasible and reliable to use the RoF algorithm to predict the height of WFZ, which is of practical significance for mining design and disaster prevention. More extensive data can lead to a more detailed database and a big data platform, which will make the model more reliable.

However, mining is a complicated industry affected by hydrogeological conditions. The uncertainty in this research lies in the absence of data on the fault, initial fissure, and pore water pressure in the rockmass. Unlike the five factors we studied, these data are hard to obtain, analyze, and quantify. If these indicators experience a large change in the same mine, a more obvious difference in the height of the WFZ could be produced, which could threaten the safety of the mine. To apply this method accurately, the hydrogeological conditions must be precisely detected. In order to prevent the movement and fracture of the rock strata, progressively more mines have adopted the cut and fill mining method. The shortcomings in this research relate to the absence of influence from filling. The effects from filling on fractures in the rockmass are very complex, and the filling materials' strength, filling rate, and compression rate may generate little effect on the height of the WFZ. Future work should consider the effect of filling on the height of the WFZ.

Finally, the results indicate that the machine learning algorithm is a promising technology, and that the resulting WFZ height can be used to manage the last resources and a water inrush reduction. Meanwhile, the empirical prediction equations on the height of the WFZ issued by the government should be updated by applying multiple methods, which can minimize the mineral resource waste and allow mining companies to obtain greater economic benefits under the premise of safety.

Author Contributions: B.D.: Conceptualization, Methodology, Software, Data curation, Writing-Original draft preparation. Y.C.: Visualization, Investigation. Supervision. Validation: Writing-Reviewing and Editing. All authors have read and agreed to the published version of the manuscript.

Funding: This study was financially supported by the national natural science foundation (51804163).

Conflicts of Interest: The authors declare no conflict of interest.

\section{References}

1. Zhao, D.; Wu, Q. An approach to predict the height of fractured water-conducting zone of coal roof strata using random forest regression. Sci. Rep. 2018, 8, 10986. [CrossRef] [PubMed]

2. Wang, S.; Li, X.; Yao, J.; Gong, F.; Li, X.; Du, K.; Tao, M.; Huang, L.; Du, S. Experimental investigation of rock breakage by a conical pick and its application to non-explosive mechanized mining in deep hard rock. Int. J. Rock Mech. Min. Sci. 2019, 122, 104063. [CrossRef]

3. Peng, K.; Liu, Z.; Zou, Q.; Wu, Q.; Zhou, J. Mechanical property of granite from different buried depths under uniaxial compression and dynamic impact: An energy-based investigation. Powder Technol. 2020, 362, 729-744. [CrossRef]

4. Peng, K.; Lv, H.; Yan, F.; Zou, Q.; Song, X.; Liu, Z. Effects of temperature on mechanical properties of granite under different fracture modes. Eng. Fract. Mech. 2020, 226, 106838.

5. Liang, W.; Zhao, G.; Wang, X.; Zhao, J.; Ma, C. Assessing the rockburst risk for deep shafts via distance-based multi-criteria decision making approaches with hesitant fuzzy information. Eng. Geol. 2019, 260, 105211. [CrossRef]

6. Liu, Z.X.; Dang, W.G.; He, X.Q.; Li, D.Y. Cancelling ore pillars in large-scale coastal gold deposit: A case study in Sanshandao gold mine, China. Trans. Nonferr. Met. Soc. China 2013, 23, 3046-3054. [CrossRef]

7. The Government Website of the Accident Inquiry System from the State Administration of Work Safety. Available online: http://media.chinasafety.gov.cn:8090/iSystem/shigumain.jsp (accessed on 23 December 2018). 
8. Peng, K.; Li, X.B.; Wan, C.C.; Peng, S.Q.; Zhao, G.Y. Safe mining technology of undersea metal mine. Trans. Nonferr. Met. Soc. China 2012, 22, 740-746. [CrossRef]

9. Majdi, A.; Hassani, F.P.; Nasiri, M.Y. Prediction of the height of destressed zone above the mined panel roof in longwall coal mining. Int. J. Coal Geol. 2012, 98, 62-72. [CrossRef]

10. Wang, F.; Xu, J.; Chen, S.; Ren, M. Method to Predict the Height of the Water Conducting Fractured Zone Based on Bearing Structures in the Overlying Strata. Mine Water Environ. 2019, 38, 767-779. [CrossRef]

11. Wang, S.; Li, X.; Wang, D. Mining-induced void distribution and application in the hydro-thermal investigation and control of an underground coal fire: A case study. Process. Saf. Environ. Prot. 2016, 102, 734-756. [CrossRef]

12. Fan, G.W.; Zhang, D.S.; Ma, L.Q. Overburden movement and fracture distribution induced by longwall mining of the shallow coal seam in the Shendong coalfield. J. China Univ. Min. Technol. 2011, 40, 196-201.

13. Cheng, W.; Zhang, N.; Han, Y.; Xiong, Z.; Qian, D. Experiment research on overburden mining-induced fracture evolution and its fractal characteristics in ascending mining. Arab. J. Geosci. 2015, 8, 13-21.

14. Zhou, N.; Zhang, J.X.; Yan, H.; Li, M. Deformation Behavior of Hard Roofs in Solid Backfill Coal Mining Using Physical Models. Energies 2017, 10, 557. [CrossRef]

15. Gang, W.; Wu, M.; Rui, W.; Hao, X.; Xiang, S. Height of the mining-induced fractured zone above a coal face. Eng. Geol. 2017, 216, 140-152.

16. Poulsen, B.A.; Adhikary, D.; Hua, G. Simulating mining-induced strata permeability changes. Eng. Geol. 2018, 237, 208-216. [CrossRef]

17. Chen, Y.; Zhao, G.; Wang, S.; Wu, H.; Wang, S. A case study on the height of a water-flow fracture zone above undersea mining: Sanshandao Gold Mine, China. Environ. Earth Sci. 2019, 78, 122. [CrossRef]

18. Jiaqi, G.; Qian, Y.; Chen, J.; Chen, F. The Minimum Safe Thickness and Catastrophe Process for Water Inrush of a Karst Tunnel Face with Multi Fractures. Processes 2019, 7, 686. [CrossRef]

19. Wen, Z.J.; Jing, S.L.; Jiang, Y.J.; Tian, L.; Wen, J.H.; Cao, Z.G.; Shi, S.S.; Zuo, Y.J. Study of the Fracture Law of Overlying Strata under Water Based on the Flow-Stress-Damage Model. Geofluids 2019, 2019, 3161852. [CrossRef]

20. Ye, Q.; Wang, W.J.; Wang, G.; Jia, Z.Z. Numerical simulation on tendency mining fracture evolution characteristics of overlying strata and coal seams above working face with large inclination angle and mining depth. Arab. J. Geosci. 2017, 10, 82. [CrossRef]

21. Sun, Y.; Zhimin, X.U.; Dong, Q. Monitoring and simulation research on development of water flowing fractures for coal mining under Xiaolangdi reservoir. Chin. J. Rock Mech. Eng. 2009, 28, 238-245.

22. Chen, L.; Fan, S.W.; Zhao, C.; Zhang, L.; Cheng, Z.H. Calculation Method of Overburden Damage Height Based on Fracture Mechanics Analysis of Soft and Hard Rock Layers. Geofluids 2019, 2019, 3790264. [CrossRef]

23. Zhang, X.Y.; Bi, B.; Yang, P.T.; Wu, Y.L.; Shen, S.S. The application of the high density resistivity method to the survey of the mined-out area. Geophys. Geochem. Explor. 2009, 3.

24. Hettama, M.; Horsrud, P.; Taugbol, K.; Friedheim, J.; Huynh, H.; Sanders, M.W.; Young, S. Development Of An Innovative High-Pressure Testing Device For The Evaluation Of Drilling Fluid Systems And Drilling Fluid Additives Within Fractured Permeable Zones. In Proceedings of the Offshore Mediterranean Conference and Exhibition, Ravenna, Italy, 28-30 March 2007.

25. Jiang, Z.; Yue, J.; Liu, Z. Application of Mine Transient Electromagnetic Method in Forecasting Goaf Water. Chin. J. Eng. Geophys. 2007, 4, 291-294.

26. Guo, W.; Zhao, G.; Lou, G.; Wang, S. A New Method of Predicting the Height of the Fractured Water-Conducting Zone Due to High-Intensity Longwall Coal Mining in China. Rock Mech. Rock Eng. 2019, 52, 2789-2802. [CrossRef]

27. Rezaei, M.; Hossaini, M.F.; Majdi, A.; Najmoddini, I. Determination of the height of destressed zone above the mined panel: An ANN model. Int. J. Min. Geo-Eng. 2017, 51, 1-7.

28. Yuan, Z.G.; Wang, H.T.; Hu, G.Z.; Liu, N.P.; Fan, X.G. Forecast model of GA-SVM for shaft-lining non-mining fracture. J. China Coal Soc. 2011, 36, 393-397.

29. Bo, L.; Chen, Y.J.G. Risk Assessment of Coal Floor Water Inrush from Underlying Aquifers Based on GRA-AHP and Its Application. Eng. Geol. 2016, 34, 143-154.

30. Liang, W.; Zhao, G.; Wu, H.; Chen, Y. Assessing the risk degree of goafs by employing hybrid TODIM method under uncertainty. Bull. Eng. Geol. Environ. 2019, 78, 3767-3782. [CrossRef] 
31. Liang, W.; Zhao, G.; Wu, H.; Dai, B. Risk assessment of rockburst via an extended MABAC method under fuzzy environment. Tunn. Undergr. Space Technol. 2019, 83, 533-544. [CrossRef]

32. Dong, L.J.; Li, X.B. Prediction of rockburst classification using Random Forest. Trans. Nonferr. Met. Soc. China 2013, 23, 472-477. [CrossRef]

33. Rodriguez, J.J.; Kuncheva, L.I.; Alonso, C.J. Rotation Forest: A New Classifier Ensemble Method. IEEE Trans. Pattern Anal. Mach. Intell. 2006, 28, 1619-1630. [CrossRef] [PubMed]

34. Liu, K.H.; Huang, D.S. Cancer classification using Rotation Forest ^. Comput. Biol. Med. 2008, 38, 601-610. [CrossRef]

35. Guo, H.; Diao, X.; Liu, H. Improving undersampling-based ensemble with rotation forest for imbalanced problem. Turk. J. Electr. Eng. Comput. Sci. 2019, 27, 1371-1386. [CrossRef]

36. Chen, W.; Shirzadi, A.; Shahabi, H.; Ahmad, B.B.; Zhang, S.; Hong, H.; Zhang, N. A novel hybrid artificial intelligence approach based on the rotation forest ensemble and naïve Bayes tree classifiers for a landslide susceptibility assessment in Langao County, China. Geomat. Nat. Hazards Risk 2017, 8, 1955-1977. [CrossRef]

37. Guo, L.B.; Sims, R.E.H. Eucalypt litter decomposition and nutrient release under a short rotation forest regime and effluent irrigation treatments in New Zealand: I. External effects. Soil Biol. Biochem. 2002, 34, 913-922. [CrossRef]

38. Sun, Y.P.; Wang, Y.F.; Zheng, X. Analysis the height of water conducted zone of coal seam roof based on GA-SVR. J. China Coal Soc. 2009, 34, 1610-1615.

39. Wu, Q.; Shen, J.; Liu, W.; Wang, Y. A RBFNN-based method for the prediction of the developed height of a water-conductive fractured zone for fully mechanized mining with sublevel caving. Arab. J. Geosci. 2017, 10, 172. [CrossRef]

40. Li, Z.; Xu, Y.; Li, L.; Zhai, C.Z. Forecast of the height of water flowing fractured zone based on BP neural networks. J. Min. Saf. Eng. 2015, 32, 905-910.

41. Miao, X.X.; Cui, X.M.; Wang, J.A.; Xu, J.L. The height of fractured water-conducting zone in undermined rock strata. Eng. Geol. 2011, 120, 32-39. [CrossRef]

42. Xie, X.; Xibing, L.I.; Shang, X.; Weng, L.; Deng, Q. Prediction of height of water flowing fractured zone based on PCA-BP neural networks model. China Saf. Sci. J. 2017, 27, 100-105.

43. Wang, S.; Huang, L.; Li, X. Analysis of rockburst triggered by hard rock fragmentation using a conical pick under high uniaxial stress. Tunn. Undergr. Space Technol. 2020, 96, 103195. [CrossRef]

44. Gadhok, N.; Kinsner, W. Rotation sensitivity of independent component analysis to outliers. In Proceedings of the Canadian Conference on Electrical \& Computer Engineering, Saskatoon, SK, Canada, 1-4 May 2005.

45. Chen, Y.; Zhao, G.; Wang, S.; Li, X. Investigations of the height of fractured zones in overburden induced by undersea mining. Arab. J. Geosci. 2019, 12, 618. [CrossRef]

46. Chai, H.B.; Zhang, J.P.; Chao, Y. Prediction of water-flowing height in fractured zone of overburden strata based on GA-SVR. J. Min. Saf. Eng. 2018, 35, 359-365.

47. Hu, X.J.; Li, W.P.; Cao, D.T.; Liu, M.C. Index of multiple factors and expected height of fully mechanized water flowing fractured zone. J. China Coal Soc. 2012, 37, 613-620.

(C) 2020 by the authors. Licensee MDPI, Basel, Switzerland. This article is an open access article distributed under the terms and conditions of the Creative Commons Attribution (CC BY) license (http://creativecommons.org/licenses/by/4.0/). 